Check for updates

Montreal

Cite this as: BMJ 2021;373:n1117 http://dx.doi.org/10.1136/bmj.n1117 Published: 29 April 2021

\title{
Covid-19: Heavy use of oxygen brings new danger to world's hospitals
}

\section{Owen Dyer}

A week marked by deadly hospital fires and a mass asphyxiation of covid-19 patients has highlighted the risks inherent to that inevitable accompaniment of a respiratory pandemic - vastly increased oxygen use.

A total of 82 people were left dead and 110 injured from a hospital fire on 24 April in Baghdad, Iraq, which began with an explosion caused by "a fault in the storage of oxygen cylinders," hospital sources told Agence France-Presse.

The oxygen was meant for patients with covid-19, who account for most of the dead. More are expected to succumb to severe burns. But most of the deaths on the day were due to people inhaling smoke or being disconnected from their ventilators for evacuation.

Over 200 patients were rescued, most being carried out by their relatives. Relatives are officially banned from Iraq's hospitals during the pandemic, but hospitals are in fact full of relatives who help to nurse their loved ones, to make up for a shortage of trained staff.

Angry questions are being asked about a disaster seen as emblematic of Iraq's dilapidated health system. The hospital had neither working sprinklers nor smoke detectors.

\section{Deaths in India}

A day earlier, 15 patients in India died in a fire in a covid intensive care unit (ICU) at Vijay Vallabh Hospital in Virar, near Mumbai. Oxygen was not the genesis of that fire, the lead investigator, Nilesh Ukunde, told the Mumbai Mirror; but, as tubes were pulled from patients' noses for evacuation, while other tubes were melted by flames, the room filled with oxygen, making the blaze far worse.

The fire began, Ukunde said, with sparks from a wiring short circuit in the ceiling above the ICU nurses' station. "Huge quantities of alcohol from sanitisers are released in the atmosphere of the ICU wards. Being lighter, it settles up on the ceiling forming a layer," he said. "In case of a short circuit, the presence of alcohol in the air results in a flashover, engulfing whatever comes in its way within a fraction of seconds."

The curtains drawn around each covid patient's bed stopped normal ventilation from clearing the alcohol in the air, he said. The sprinklers did not work, although the hospital had passed a fire audit. The fire was the second deadly blaze in a covid ICU in India's Maharashtra state this month. Four patients with covid-19 were killed in a fire at a private hospital in Wadi, Nagpur district, on 9 April.

An oxygen leak at another hospital in Maharashtra state on 21 April left 22 covid-19 patients dead, as the pressure feeding their tubes fell to zero during an attempted refill of the hospital's main tank. The hospital was treating 150 patients with covid-19, of whom 15 were on ventilators.

Television cameras were present as clouds of white gas-water vapour condensing on the cold oxygen-filled parts of the hospital and the street outside. They also showed staff frantically trying to resuscitate patients as relatives cried. A woman told TV9 that her mother began to gasp as soon as the oxygen supply stopped. "She died, and so did everyone in her ward," the woman said.

\section{Oxygen supplies}

India's massive demand for oxygen has created both a bustling black market and a large charitable movement providing cylinders to patients with covid-19. Some hospitals tell patients to bring their own oxygen, while patients who cannot find a hospital bed often self-treat with oxygen at home. These patients may struggle as new government regulations instruct industrial oxygen suppliers to give their product directly to hospitals, rather than filling up individual cylinders.

Some hospitals also reported being close to running out of oxygen, particularly in Delhi and in neighbouring Uttar Pradesh state. The chief minister of Uttar Pradesh, Yogi Adityanath, of India's ruling BJP party, told a meeting of police chiefs to take action against hospitals that reported oxygen shortages to "create fear."

"Keep a watch on such people. Duly investigate all such incidents," he said in a statement released later by his office. "If the scarcity was reported just to create fear, then strict action should be taken against [that] hospital." 